\title{
Molecular Characterization and Antifungal Susceptibility of Clinical Fusarium Species From Brazil
}

\author{
Patricia F. Herkert ${ }^{1,2,3 *}$, Abdullah M. S. Al-Hatmi ${ }^{3,4,5}$, Gabriel L. de Oliveira Salvador 6 , \\ Marisol D. Muro ${ }^{7}$, Rosângela L. Pinheiro ${ }^{7}$, Márcio Nucci ${ }^{8}$, Flávio Queiroz-Telles ${ }^{9}$, \\ G. Sybren de Hoog ${ }^{3,4,10}$ and Jacques F. Meis ${ }^{3,11}$
}

\begin{abstract}
${ }^{1}$ Instituto Carlos Chagas, Fundação Oswaldo Cruz, Curitiba, Brazil, ${ }^{2}$ Instituto Nacional de Ciência e Tecnologia de Inovação em Doenças de Populações Negligenciadas, Brasilia, Brazil, ${ }^{3}$ Centre of Expertise in Mycology Radboudumc/CWZ, Nijmegen, Netherlands, ${ }^{4}$ Department of Medical Mycology, Westerdijk Fungal Biodiversity Institute, Utrecht, Netherlands, ${ }^{5}$ Directorate General of Health Services, Ministry of Health, Ibri Hospital, Ibri, Oman, ${ }^{6}$ Department of Internal Medicine, Federal University of Paraná, Curitiba, Brazil, ' Laboratory of Mycology, Hospital de Clínicas, Federal University of Paraná, Curitiba, Brazil, ${ }^{8}$ Department of Internal Medicine, Hematology Service, University Hospital, Federal University of Rio de Janeiro, Rio de Janeiro, Brazil, ${ }^{9}$ Infectious Diseases Unit, Department of Public Health, Hospital de Clínicas, Federal University of Paraná, Curitiba, Brazil, ${ }^{10}$ Postgraduate Program in Microbiology, Parasitology and Pathology, Biological Sciences, Department of Basic Pathology, Federal University of Paraná, Curitiba, Brazil, "1 Department of Medical Microbiology and Infectious Diseases, Canisius-Wilhelmina Hospital, Nijmegen, Netherlands
\end{abstract}

\section{OPEN ACCESS}

Edited by:

Saad J. Taj-Aldeen, Hamad Medical Corporation, Qatar

Reviewed by: lan Macreadie,

RMIT University, Australia Hamid Badali,

Mazandaran University of Medical Sciences, Iran

*Correspondence:

Patricia F. Herkert patriciaherkert@gmail.com

Specialty section: This article was submitted to Fungi and Their Interactions,

a section of the journal

Frontiers in Microbiology

Received: 30 January 2019

Accepted: 25 March 2019

Published: 10 April 2019

Citation:

Herkert PF, Al-Hatmi AMS, de Oliveira Salvador GL, Muro MD,

Pinheiro RL, Nucci M,

Queiroz-Telles F, de Hoog GS and

Meis JF (2019) Molecular

Characterization and Antifungal Susceptibility of Clinical Fusarium

Species From Brazil.

Front. Microbiol. 10:737.

doi: 10.3389/fmich.2019.00737
Fusarium is widely distributed in the environment and is involved with plant and animal diseases. In humans, several species and species complexes (SC) are related to fusariosis, i.e., F. solani SC, F. oxysporum SC, F. fujikuroi SC, F. dimerum, F. chlamydosporum, F. incarnatum-equiseti, and F. sporotrichoides. We aimed to investigate the susceptibility of Fusarium clinical isolates to antifungals and azole fungicides and identify the species. Forty-three clinical Fusarium isolates were identified by sequencing translation elongation factor 1-alpha (TEF1 $\alpha)$ gene. Antifungal susceptibility testing was performed to the antifungals amphotericin B, itraconazole, voriconazole, posaconazole, and isavuconazole, and the azole fungicides difenoconazole, tebuconazole, and propiconazole. The isolates were recovered from patients with median age of 36 years (range 2-78 years) of which 21 were female. Disseminated fusariosis was the most frequent clinical form $(n=16,37.2 \%)$ and acute lymphoblastic leukemia ( $n=7 ; 16.3 \%$ ) was the most commonly underlying condition. A few species described in Fusarium solani SC have recently been renamed in the genus Neocosmospora, but consistent naming is yet not possible. Fusarium keratoplasticum FSSC 2 ( $n=12$ ) was the prevalent species, followed by F. petroliphilum FSSC $1(n=10)$, N. gamsii FSSC $7(n=5), N$. suttoniana FSSC $20(n=3)$, F. solani sensu stricto FSSC $5(n=2)$, Fusarium sp. FSSC $25(n=2)$, Fusarium sp. FSSC $35(n=1)$, Fusarium sp. FSSC18 $(n=1)$, F. falciforme FSSC $3+4(n=1)$, F. pseudensiforme $(n=1)$, and F. solani f. xanthoxyli $(n=1)$. Amphotericin B had activity against most isolates although MICs ranged from 0.5 to $32 \mu \mathrm{g} \mathrm{mL}^{-1}$. Fusarium keratoplasticum showed high MIC values (8-> $32 \mu \mathrm{g} \mathrm{mL}^{-1}$ ) for itraconazole, voriconazole, posaconazole, and isavuconazole. Among agricultural fungicides, difenoconazole had the lowest activity against FSSC with MICs of $>32 \mu \mathrm{g} \mathrm{mL}^{-1}$ for all isolates.

Keywords: fusariosis, antifungal, fungicide, susceptibility, Fusarium, molecular identification 


\section{INTRODUCTION}

The fungal genus Fusarium is widely distributed as saprobes in the environment but is also able to cause cross-kingdom disease in both plants and mammals (Gauthier and Keller, 2013; van Diepeningen and de Hoog, 2016). In humans, the disease may manifest in different ways, depending on the portal of entry and the host's immune status. Invasive fusariosis is the most severe manifestation that predominantly affects immunocompromised hosts with hematological malignancies, neutropenia, or glucocorticoid exposure (Nucci et al., 2003, 2004, 2019; de Souza et al., 2014). In immunocompetent hosts, the fungus may cause onychomycosis (Guevara-Suarez et al., 2016), keratitis (Tupaki-Sreepurna et al., 2017a) or other (sub)cutaneous disorders. The most frequent fungal diseases caused by Fusarium species are onychomycosis and keratitis, although other clinical presentations are also observed, such as fungemia, mycetoma, skin infection, lung disease (including allergic disease, hypersensitivity pneumonitis, colonization of a pre-existing cavity, pneumonia in severely immunocompromised patients), and other rare infections (endocarditis, urinary tract infection, osteomyelitis, etc.) (Sierra-Hoffman et al., 2005; Su et al., 2007; Nucci et al., 2015; Kassar et al., 2016).

Species belonging to Fusarium are distributed into several species complexes (SC), some of which are important in human and veterinary mycology, particularly F. solani SC, F. oxysporum SC, F. fujikuroi SC, F. dimerum, F. chlamydosporum, F. incarnatum-equiseti, and F. sporotrichoides (van Diepeningen et al., 2014; Salah et al., 2015; Al-Hatmi et al., 2016a; Hassan et al., 2016). Fusarium graminearum, F. culmorum, F. fujikuroi SC, F. solani SC, and F. oxysporum SC may additionally be found as plant pathogens in maize, wheat, rice, soybean, and tomato crops (Basler, 2016; Costa et al., 2016; Kim et al., 2016; Manzo et al., 2016). Some Fusarium species produce mycotoxins during growth in plant tissue, which may contaminate cereal grains and derivatives, making them unsuitable for consumption and causing great agricultural losses (Milicevic et al., 2010; Sobrova et al., 2010).

In attempts to reduce agricultural losses caused by fungal diseases, many strategies have been used, including augmentation of plant resistance, spraying of chemicals, biological control, integrated disease management (Singh et al., 2016), and fungicide use, especially azoles (Hof, 2001). The continuing uncontrolled use of fungicides may lead to selective pressure on environmental fungi (Deising et al., 2008). Due to the structural similarity of azoles used in agriculture and medicine, cross-resistance may be observed in clinical fungi (Meis et al., 2016; Verweij et al., 2016). Studies have been performed to test the hypothesis whether fungicide use in agroecosystems may lead to antifungal resistance in Aspergillus fumigatus in the clinic (Snelders et al., 2008; Chowdhary et al., 2012, 2013; Meis et al., 2016; Alvarez-Moreno et al., 2017).

In the medical field, amphotericin B, voriconazole, and posaconazole are the main antifungal drugs recommended for prophylaxis and treatment of human fusariosis (Lortholary et al., 2010; Tortorano et al., 2014; Clark et al., 2015; Nucci et al., 2015; Taj-Aldeen et al., 2016; Al-Hatmi et al., 2018b). Most Fusarium species exhibit high minimal inhibitory concentrations (MICs) to currently used antifungals, especially azoles (Katiyar and Edlind, 2009; Fan et al., 2013; Al-Hatmi et al., 2015).

Here we aimed to investigate the susceptibility of Fusarium clinical isolates to commonly used antifungals and fungicides and identify the species. For this study, we used strains that were isolated from patients with fusariosis diagnosed in two tertiary Brazilian hospitals in southern Brazil.

\section{MATERIALS AND METHODS}

\section{Strains and Clinical Data}

Forty-three clinical Fusarium isolates were available from the Laboratory of Mycology at the Federal University of Paraná Hospital, Curitiba, Brazil and Federal University of Rio de Janeiro Hospital, Rio de Janeiro, Brazil, recovered from 40 patients cared between 1985 and 2015. Three patients (32, 36, and 38) had each two isolates recovered, as specified in the Table 1. The patient's medical records were reviewed to collect minimal clinical information such as age, gender, treatment, and outcome.

\section{DNA Isolation, PCR, and Sequencing}

Fusarium isolates were cultured on Sabouraud dextrose agar plus chloramphenicol (SDA; Difco Laboratories, Detroit, MI, United States). Culture plates were incubated at 26 and $37^{\circ} \mathrm{C}$ and observed daily for growth up to 7 days. Initial identification of Fusarium isolates was based on macroscopic colony morphology and microscopic features in a lacto-phenol wet mount preparation according to standard laboratory procedures. Final identification was done using molecular methods. DNA extraction was performed as described by Khodavaisy et al. (2016). Conidia were suspended in $400 \mu \mathrm{L}$ bacterial lysis buffer (Roche Diagnostics, Almere, Netherlands) followed by mechanical lysis in a MagNA Lyser (Roche Diagnostics) for $30 \mathrm{~s}$ at $4,500 \times \mathrm{g}$. Cells were inactivated for $10 \mathrm{~min}$ by heating at $100^{\circ} \mathrm{C}$ and $200 \mu \mathrm{L}$ of the solution was used for automated DNA extraction by using the MagNA Pure 96 platform (Roche Diagnostics) with a final elution volume of $100 \mu \mathrm{L}$.

Fragments of the translation elongation factor 1-alpha (TEF1 $\alpha$ ) gene were amplified and sequenced using PCR protocols following the methods published by Al-Hatmi et al. (2014) with primers EF1 (5'-ATGGGTAAGGA(A/G)GACAAGAC-3') and EF2 (5'-GGA(G/A)GTACCAGT(G/C)ATCATGTT-3') (O'Donnell et al., 1998). Sequencing reaction mixtures contained $1 \mathrm{ng} / \mu \mathrm{L}$ of template DNA, $1 \mathrm{pmol} / \mu \mathrm{L}, 0.7 \mu \mathrm{L}$ of BigDye ${ }^{\mathrm{TM}}$ terminator (Applied Biosystems, Foster City, CA, United States), $3 \mu \mathrm{L}$ buffer and ultra-pure water to $10 \mu \mathrm{L}$ final volume. Sequencing PCR was performed as follows: $95^{\circ} \mathrm{C}$ for $1 \mathrm{~min}$, followed by 30 cycles consisting of $95^{\circ} \mathrm{C}$ for $10 \mathrm{~s}, 50^{\circ} \mathrm{C}$ for $5 \mathrm{~s}$ and $60^{\circ} \mathrm{C}$ for $2 \mathrm{~min}$. Sequencing was done on an $\mathrm{ABI} 3730 \mathrm{xL}$ automatic sequencer (Applied Biosystems).

\section{Alignment and Phylogenetic Analyses}

For preliminary identification, a homology search for the sequences of TEF1 $\alpha$ was done using the BLAST tool in 
TABLE 1 | Fusarium isolates data.

\begin{tabular}{|c|c|c|c|c|c|c|c|c|}
\hline Isolate no. & $\begin{array}{l}\text { Species } \\
\text { complex }\end{array}$ & Species & Patient & Type of fusariosis & $\begin{array}{l}\text { Underlying } \\
\text { disease }\end{array}$ & Source & Treatment & $\begin{array}{c}\text { GenBank } \\
\text { accession no. }\end{array}$ \\
\hline FuO2 & FSSC25 & Fusarium sp. & 1 & Disseminated & Unknown & Blood & VOR & MG738163 \\
\hline Fu14 & FSSC2 & F. keratoplasticum & 2 & Disseminated & AML & Skin & VOR & MG738189 \\
\hline Fu27 & FSSC2 & F. keratoplasticum & 3 & Cutaneous & $\begin{array}{c}\text { Arterial insufficiency } \\
\text { on legs }\end{array}$ & Skin & VOR & MG738193 \\
\hline Fu34 & FSSC5 & F. solani s.s. & 4 & Keratitis & None & Eye & VOR & MG738195 \\
\hline Fu37 & FSSC2 & F. keratoplasticum & 5 & Cutaneous & None & Skin & VOR & MG738184 \\
\hline Fu50 & FSSC1 & F. petroliphilum & 6 & Disseminated & Myelodysplasia & Skin & AMB & MG738167 \\
\hline Fu51 & FSSC1 & F. petroliphilum & 7 & Disseminated & AML & Blood & FLU & MG738168 \\
\hline Fu56 & FFSC & F. napiforme & 8 & Cutaneous & Fanconi anemia & Blood & VOR + AMB & MG738202 \\
\hline Fu66 & $\mathrm{FSSC} 3+4$ & F. falciforme & 9 & Keratitis & None & Eye & VOR & MG738197 \\
\hline Fu71 & FFSC & F. verticillioides & 10 & Disseminated & AML & Skin & VOR & MG738201 \\
\hline Fu72 & FSSC7 & N. gamsii & 11 & Cutaneous & ALL & Blood & VOR & MG738177 \\
\hline Fu73 & FSSC7 & N. gamsii & 12 & Disseminated & $\begin{array}{l}\text { Non-Hodgkin } \\
\text { lymphoma }\end{array}$ & Skin & VOR + AMB & MG738178 \\
\hline Fu75 & FSSC1 & F. petroliphilum & 13 & Keratitis & None & Eye & not done & MG738169 \\
\hline Fu77 & FSSC2 & F. keratoplasticum & 14 & Disseminated & $\begin{array}{c}\text { Purpura } \\
\text { amegakaryocytic }\end{array}$ & Skin & not done & MG738190 \\
\hline Fu78 & FFSC & F. subglutinans & 15 & Disseminated & Aplastic anemia & Blood & VOR + AMB & MG738203 \\
\hline Fu80 & FSSC7 & N. gamsii & 16 & Unknown & Unknown & Skin & Unknown & MG738179 \\
\hline Fu86 & FSSC25 & Fusarium sp. & 17 & Unknown & Unknown & Skin & Unknown & MG738164 \\
\hline Fu87 & FSSC & Fusarium sp. & 18 & Cutaneous & ALL & Blood & VOR & MG738166 \\
\hline Fu89 & FSSC35 & Fusarium sp. & 19 & Disseminated & Unknown & Blood & VOR & MG738162 \\
\hline Fu92 & FSSC1 & F. petroliphilum & 20 & Cutaneous & Aplastic anemia & Skin & VOR + AMB & MG738170 \\
\hline Fu93 & FSSC20 & N. suttoniana & 21 & Disseminated & $\mathrm{CML}$ & Skin & VOR + AMB & MG738198 \\
\hline Fu94 & FSSC & F. xanthoxyli & 22 & Disseminated & Unknown & Skin & VOR & MG738182 \\
\hline Fu96 & FSSC2 & F. keratoplasticum & 23 & Disseminated & ALL & Skin & VOR & MG738185 \\
\hline Fu97 & FSSC2 & F. keratoplasticum & 24 & Disseminated & ALL & $\begin{array}{l}\text { Endotracheal } \\
\text { aspirate }\end{array}$ & VOR + AMB & MG738194 \\
\hline Fu99 & FSSC1 & F. petroliphilum & 25 & Cutaneous & Aplastic anemia & Skin & VOR + ISA & MG738171 \\
\hline Fu100 & FSSC20 & N. suttoniana & 26 & Keratitis & None & Eye & VOR & MG738199 \\
\hline Fu101 & FSSC2 & F. keratoplasticum & 27 & Disseminated & $\begin{array}{l}\text { Myocardium } \\
\text { revascularization }\end{array}$ & Skin & VOR & MG738183 \\
\hline Fu103 & FSSC20 & N. suttoniana & 28 & Keratitis & None & Eye & VOR & MG738200 \\
\hline Fu105 & FSSC2 & F. keratoplasticum & 29 & Disseminated & Myelodysplasia & Skin & VOR & MG738191 \\
\hline Fudm2 & FSSC7 & N. gamsii & 30 & Disseminated & ALL & Blood & VOR + AMB & MG738180 \\
\hline FuB302.1 & FSSC2 & F. keratoplasticum & 31 & Unknown & $\begin{array}{l}\text { Rheumatoid } \\
\text { arthritis }\end{array}$ & Skin & VOR & MG738192 \\
\hline FuB371 & FSSC5 & F. solani s.s. & 32 & Unknown & ALL & Skin & VOR & MG738196 \\
\hline FuB391 & FSSC33 & F. pseudensiforme & 33 & Unknown & Unknown & Skin & Unknown & MG738161 \\
\hline FuB478 & FSSC2 & F. keratoplasticum & 34 & Unknown & AML & Skin & AMB & MG738186 \\
\hline FuB560 & FSSC7 & N. gamsii & 35 & Unknown & $\mathrm{CML}$ & Skin & $\begin{array}{c}\text { VOR + lipid } \\
\text { AMB }\end{array}$ & MG738181 \\
\hline FuB604 & FSSC1 & F. petroliphilum & 36 & Unknown & ALL & Synovial fluid & VOR & MG738172 \\
\hline FuB665 & FSSC1 & F. petroliphilum & 36 & Unknown & ALL & Synovial fluid & VOR & MG738173 \\
\hline FuB817 & FSSC1 & F. petroliphilum & 37 & Unknown & Myelodysplasia & Skin & VOR & MG738174 \\
\hline FuB920 & FSSC1 & F. petroliphilum & 32 & Unknown & ALL & Synovial fluid & VOR & MG738175 \\
\hline FuB935 & FSSC2 & F. keratoplasticum & 38 & Unknown & AML & Skin & $\begin{array}{l}\text { VOR + lipid } \\
\text { AMB }\end{array}$ & MG738187 \\
\hline FuB936 & FSSC2 & F. keratoplasticum & 38 & Unknown & AML & Skin & $\begin{array}{c}\text { VOR + lipid } \\
\text { AMB }\end{array}$ & MG738188 \\
\hline FuH79A & FSSC18 & Fusarium sp. & 39 & Unknown & AML & Blood & $\begin{array}{c}\text { VOR + lipid } \\
\text { AMB }\end{array}$ & MG738165 \\
\hline FuH05 & FSSC1 & F. petroliphilum & 40 & Unknown & Unknown & Blood & Unknown & MG738176 \\
\hline
\end{tabular}

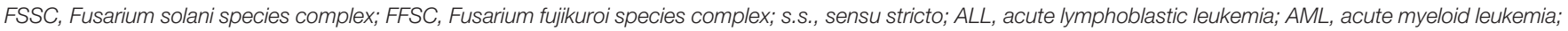
$C M L$, chronic myeloid leukemia; AMB, amphotericin B; FLU, fluconazole; ISA, isavuconazole; VOR, voriconazole; Unknown, no data available. 
NCBI database, the CBS database, FUSARIUM-ID (Geiser et al., 2004) and the Fusarium MLST (O'Donnell et al., 2010) database down to species and haplotype level. DNA sequences were edited, and consensus sequences were assembled by the SeqMan package of Lasergene software (DNAStar, Madison, WI, United States). Retrieved alignments were manually corrected to avoid mis-paired bases. Sequences were exported as FASTA files. Sequences of TEF1 $\alpha$ were aligned with MAFFT program ${ }^{1}$ and adjusted in MEGA6 (Tamura et al., 2013). The best-fit model of evolution was determined by MEGA6. Maximum likelihood (ML) analysis was done with RAxML-VI-HPC v. 7.0.3 with non-parametric bootstrapping using 1000 replicates. GenBank accession numbers are shown in Table 1.

\section{Antifungal Susceptibility Testing}

Antifungal susceptibility testing by the broth microdilution method was performed according to the CLSI protocol M38-A2 (Clinical and Laboratory Standards Institute [CLSI], 2008). Antifungal agents tested were amphotericin B (Bristol Myers Squibb, Woerden, Netherlands), itraconazole (Janssen Pharmaceutica, Beerse, Belgium), voriconazole (Pfizer, Sandwich, United Kingdom), posaconazole (Merck, NJ, United States) and isavuconazole (Basilea Pharmaceutica, Basel, Switzerland). The fungicides used were difenoconazole, tebuconazole and propiconazole (all from Sigma-Aldrich, St. Louis, MO, United States). The concentrations of antifungals ranged from 0.031 to $32 \mu \mathrm{g} \mathrm{mL}^{-1}$. Fusarium isolates were cultured onto Sabouraud glucose agar until sporulation at $30^{\circ} \mathrm{C}$ and the inocula were adjusted to $1.8-3 \times 10^{6} \mathrm{CFU} / \mathrm{mL}$ in saline supplemented with $0.05 \%$ Tween 20 to perform the test. Microdilution plates were incubated at $35^{\circ} \mathrm{C}$ for $48 \mathrm{~h}$ and the MICs were defined as the lowest concentration able to complete growth inhibition when compared with the drug free growth control. Aspergillus flavus ATCC 204304, Candida parapsilosis ATCC 22019 and C. krusei ATCC 6258 reference strains were used as quality controls (Clinical and Laboratory Standards Institute [CLSI], 2008). Interpretation of the MIC values was based on Epidemiological Cutoff Values (ECV) according to previous literature data (Espinel-Ingroff et al., 2016). MIC $_{50}$ and MIC $_{90}$ were obtained by ordering the data for each antifungal in ascending order and selecting the median and 90th quantile, respectively. Geometric mean MICs were calculated using Microsoft Office Excel 2010 software (Microsoft, Redmond, WA, United States). When the MIC was more or less than dilutions tested, $1 \log _{2}$ dilution higher or $1 \log _{2}$ dilution lower was considered for calculating the geometric mean.

\section{RESULTS}

\section{Clinical Data}

The median age of the 40 patients was 36 years (range 2-78 years) and 21 were female. Disseminated fusariosis was the most frequent clinical form $(n=16,37.2 \%)$, followed by cutaneous infections $(n=7 ; 16.3 \%)$ and keratitis $(n=5$;

${ }^{1}$ www.ebi.ac.uk/Tools/msa/mafft/
$11.6 \%)$. Fusarium strains were isolated most frequently from the skin $(n=24 ; 55.8 \%)$, blood $(n=10 ; 23.2 \%)$, and eye $(n=5 ; 11.6 \%)$. Acute lymphoblastic leukemia $(n=7 ; 16.3 \%)$ and acute myeloid leukemia $(n=6 ; 13.9 \%)$ were the most commonly underlying conditions. Twelve out of 16 cases of disseminated fusariosis occurred in patients with hematological malignancies. Voriconazole monotherapy was the treatment in $21(48.8 \%)$ patients, 13 of which $(61.9 \%)$ had a favorable response to therapy. Combination therapy with voriconazole and deoxycholate amphotericin B was given to 7 (16.3\%) patients, and voriconazole plus liposomal amphotericin B in 3 patients (7\%). Other therapies were deoxycholate amphotericin $\mathrm{B}$ alone $(n=2 ; 4.7 \%)$, fluconazole alone $(n=1 ; 2.3 \%)$, and voriconazole associated with itraconazole $(n=1 ; 2.3 \%)$. For $2(4.7 \%)$ patients no therapy was given. Information about treatment was not available in 6 cases. The isolates and respective patients' clinical data are shown in Table 1.

\section{Molecular Identification and Phylogeny}

Phylogenetic analysis based on TEF1 $\alpha$ sequences was conducted in order to position the isolates in the Fusarium solani complex and their respective species complexes (Figure 1). The analysis included 55 sequences from different species, and one outgroup taxa (NRRL 22316 F. staphyleae). Within FSSC, F. keratoplasticum FSSC $2(n=12)$ was most often involved in cases of fusariosis, followed by F. petroliphilum FSSC $1(n=10)$, Neocosmospora gamsii FSSC $7(n=5)$, N. suttoniana FSSC 20 $(n=3)$, F. solani sensu stricto FSSC $5(n=2)$, Fusarium sp. FSSC $25(n=2)$, Fusarium sp. FSSC $35(n=1)$, Fusarium sp. FSSC $18(n=1), F$. falciforme FSSC $3+4(n=1), F$. pseudensiforme $(n=1)$, and F. solani f. xanthoxyli $(n=1)$. One isolate clustered in a separate clade (unknown species/haplotype) forming a distinct, well-supported, unnamed lineage and which matched only with a single strain from Colombia (LEMM 110739, GenBank accession no. LN827969, misidentified as Fusarium solani). We also identified the following members of the Fusarium fujikuroi species complex (FFSC): F. subglutinans $(n=1), F$. verticillioides $(n=1)$, and $F$. napiforme $(n=1)$ which are not included in the phylogenetic analysis.

\section{Antifungal Susceptibility Profiles}

MICs are shown in Tables 2, 3. Amphotericin B had relatively high activity with MICs ranging from 0.5 to $32 \mu \mathrm{g} \mathrm{mL}^{-1}$, except for the isolates Fu73 (novel lineage) and Fu80 (Neocosmospora gamsii FSSC7), which showed MIC values of 8 and $32 \mu \mathrm{g} \mathrm{mL}^{-1}$, respectively. All isolates exhibited high MICs to itraconazole with MICs $>32 \mu \mathrm{g} \mathrm{mL} \mathrm{mL}^{-1}$. The FSSC had MIC values of posaconazole and difenoconazole higher than $32 \mu \mathrm{g} \mathrm{mL}^{-1}$. Other azoles showed to be less effective against FSSC isolates with high MIC values of $8->32 \mu \mathrm{g} \mathrm{mL}^{-1}$. Fusarium keratoplasticum showed high MIC values $\left(8->32 \mu \mathrm{g} \mathrm{mL}{ }^{-1}\right)$ for itraconazole, voriconazole, posaconazole and isavuconazole. In counterpart, azoles showed activity against FFSC with MIC values ranges of 1-8 $\mu \mathrm{g} \mathrm{mL}^{-1}$ and with only one isolate of F. napiforme showing MIC of $>32 \mu \mathrm{g} \mathrm{mL}^{-1}$ for posaconazole.

Among the agricultural fungicides, difenoconazole had the lowest activity against FSSC with MICs of $>32 \mu \mathrm{g} \mathrm{mL}^{-1}$ for all 


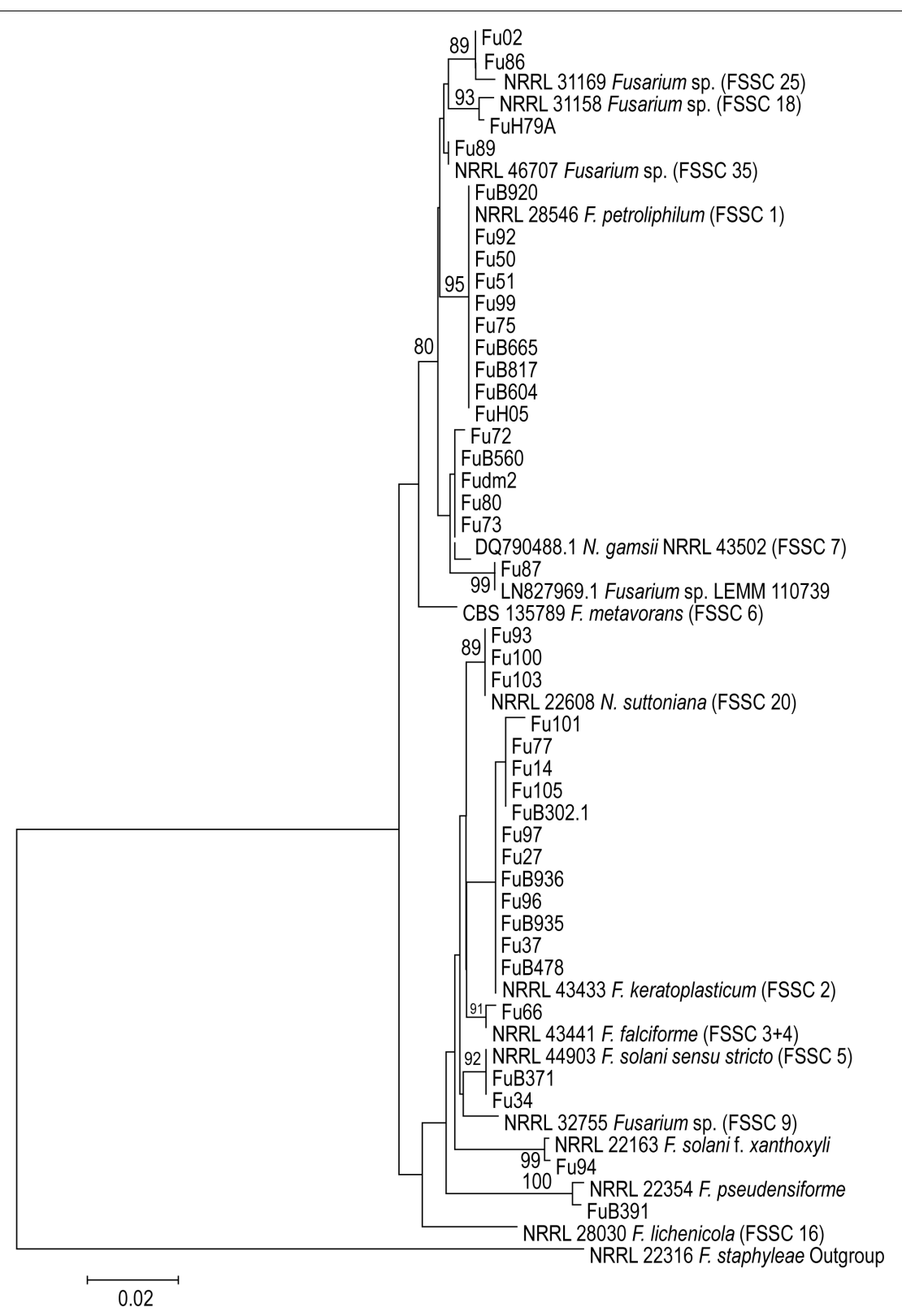

FIGURE 1 | Maximum likelihood (ML) phylogenetic tree created from TEF1 sequences of 55 Fusarium sequences. Total alignment length is 707 bp. Thousand bootstrap-replications. The tree was rooted with NRRL 22316 F. staphyleae.

isolates, followed by propiconazole and tebuconazole. In contrast, the three fungicides showed activity against FFSC, with MIC ranges of $2-8 \mu \mathrm{g} \mathrm{mL}^{-1}$.

\section{DISCUSSION}

Invasive fusariosis is a severe disease that affects immunocompromised patients, mostly those with underlying hematological malignancies (Nucci et al., 2003, 2013; Nucci and Anaissie, 2007; Campo et al., 2010; Carlesse et al., 2017). In agreement with the literature, the present study found the majority of disseminated cases of fusariosis (11/16) occurring in patients with acute lymphoblastic leukemia and acute myeloid leukemia. Disseminated fusariosis in these patients has a poor prognosis and mortality rates are close to 75\% (Nucci and Anaissie, 2007; Campo et al., 2010). The treatment of this infection is a challenge and in the absence of better alternatives, voriconazole and amphotericin B are the most recommended therapies (Nucci and Anaissie, 2007; Nucci et al., 2014; Tortorano et al., 2014; Al-Hatmi et al., 2017).

Results from our sequence analysis show that twelve phylogenetic species within the solani complex were involved in 
TABLE 2 | Minimal inhibitory concentrations of Fusarium clinical isolates.

\begin{tabular}{|c|c|c|c|c|c|c|c|c|c|c|c|c|c|}
\hline \multirow[t]{2}{*}{ Species complex } & \multirow[t]{2}{*}{ Antifungal } & \multicolumn{12}{|c|}{ No. of isolates per MIC value $\left(\mu \mathrm{g} \mathrm{mL}^{-1}\right)$} \\
\hline & & 0.031 & 0.062 & 0.125 & 0.25 & 0.5 & 1 & 2 & 4 & 8 & 16 & 32 & $>32$ \\
\hline \multirow{8}{*}{$\operatorname{FSSC}(n=40)$} & Amphotericin B & & & & & 10 & 16 & 9 & 4 & & & 1 & \\
\hline & Itraconazole & & & & & & & & & & & & 40 \\
\hline & Voriconazole & & & & & & & 1 & 2 & 21 & 7 & 3 & 6 \\
\hline & Posaconazole & & & & & & & & & & & & 40 \\
\hline & Isavuconazole & & & & & & & & & & & 10 & 30 \\
\hline & Difenoconazole & & & & & & & & & & & & 40 \\
\hline & Tebuconazole & & & & & & & & & & 3 & 4 & 33 \\
\hline & Propiconazole & & & & & & & & & & 1 & & 39 \\
\hline \multirow[t]{8}{*}{$\operatorname{FFSC}(n=3)$} & Amphotericin B & & & & & & 1 & 2 & & & & & \\
\hline & Itraconazole & & & & & & & & & & & & 3 \\
\hline & Voriconazole & & & & & & & 2 & 1 & & & & \\
\hline & Posaconazole & & & & & 1 & 1 & & & & & & 1 \\
\hline & Isavuconazole & & & & & & & & 3 & & & & \\
\hline & Difenoconazole & & & & & & & & 1 & 2 & & & \\
\hline & Tebuconazole & & & & & & & 1 & 2 & & & & \\
\hline & Propiconazole & & & & & & & 1 & & 2 & & & \\
\hline
\end{tabular}

FSSC, Fusarium solani species complex; FFSC, Fusarium fujikuroi species complex; MIC, minimum inhibitory concentration. The modes are depicted in bold.

40 cases and responsible for $93 \%$ of the fusariosis in this study. In addition, three species were identified as belonging to the fujikuroi complex (7\%). Of the 12 species and haplotypes of FSSC where the 40 strains were distributed, six belonged to previously described Fusarium species or varieties (F. keratoplasticum, F. falciforme, F. petroliphilum, Fusarium solani sensu stricto, F. ambrosium, and F. solani f. xanthoxyli), three to known haplotypes (FSSC 25, FSSC 35, FSSC 18, respectively), while two clades were recently described in Neocosmospora [FSSC $7=N$. gamsii, FSSC $20=N$. suttoniana (Figure 1)]; note that according to these authors (Sandoval-Denis and Crous, 2018) the entire Fusarium solani species complex phylogenetically constitutes a separate genus, Neocosmospora, but not all extant species have consistently been denominated, resulting in the use of two generic names for closely related species. One strain (Fu87) was identified as a novel phylogenetic lineage within FSSC and matched with LEMM 110739, which was previously reported by Guevara-Suarez et al. (2016) from an onychomycosis case. Numerous haplotypes and the newly reported lineage have remained yet unnamed. In the present study, F. keratoplasticum (FSSC 2) was the most often recorded species (28\%), followed by F. petroliphilum (FSSC 1, 23.3\%), which agrees with data of O'Donnell et al. (2007). In accordance with literature data (O’Donnell et al., 2007; Walther et al., 2017) we also encountered Fusarium solani sensu stricto (FSSC 5) causing keratitis.

Members of FSSC with a significant role in clinical infections in our data set comprised $F$. falciforme (FSSC 3+4), F. keratoplasticum (FSSC 2), F. lichenicola (FSSC 16), F. metavorans (FSSC 6), F. petroliphilum (FSSC 1), F. pseudensiforme (FSSC 33), and F. solani sensu stricto (FSSC 5) (Al-Hatmi et al., 2018a; Boral et al., 2018). Another lineage associated with opportunistic infections in FSSC that has been named is FSSC 27 (Phialophora cyanescens = Cylindrocarpon cyanescens), which was recently recombined as Neocosmospora cyanescens, MB 813864 (Summerbell and Scott, 2016). This species of FSSC lacks a name in Fusarium, while conversely F. solani f. xanthoxyli has no name in Neocosmospora; thus, consistent naming of the fungi in FSSC is impossible. Recently, a study from Japan also reported that haplotypes FSSC 9 and FSSC 18 are associated with opportunistic infections and with mycotic keratitis (Muraosa et al., 2017), while a German report found FSSC 9 and FSSC 25 to be involved in endophthalmitis (Walther et al., 2017). Literature data indicate that species within FSSC are the main cause of fusariosis worldwide (Scheel et al., 2013; Hassan et al., 2016; Tupaki-Sreepurna et al., 2017a). Fusarium keratoplasticum has been reported as the etiologic cause of disseminated fusariosis in hematologic patients (García-Ruiz et al., 2015; Chiewchanvit et al., 2017), as well as keratitis (TupakiSreepurna et al., 2017a), onychomycoses (Guevara-Suarez et al., 2016; Gupta et al., 2016) and eumycetoma (Al-Hatmi et al., 2017). In addition, F. keratoplasticum is an important veterinary etiologic agent, causing disease in equine and marine vertebrates as well as in invertebrates (O'Donnell et al., 2016).

In the present study, we identified additional species and haplotypes for the first time from clinical samples, including F. pseudensiforme (FSSC 33), F. solani f. xanthoxyli (FSSC 22), N. gamsii (haplotype 7 - FSSC 7), N. suttoniana (haplotype 20 -FSSC 20), Fusarium sp. (FSSC 25), and Fusarium sp. (FSSC 35) (Figure 1), but confirmed case reports are as yet lacking. All these haplotypes are phylogenetically distinct from described species but remain unnamed as molecular siblings. Our data suggest that these additional species/haplotypes might be of importance for human health, although on the other hand it remains questionable whether formal description of the FSSC lineages as formal species is meaningful. Using TEF1 $\alpha$ sequences strain Fu87 matched with an undescribed lineage (LEMM 110739) previously reported by Guevara-Suarez et al. (2016) from clinical samples in Colombia. 
TABLE 3 | Individual minimal inhibitory concentration $\left(\mu \mathrm{g} \mathrm{mL}^{-1}\right.$ ) of all Fusarium spp. and Neocosmospora spp. isolates.

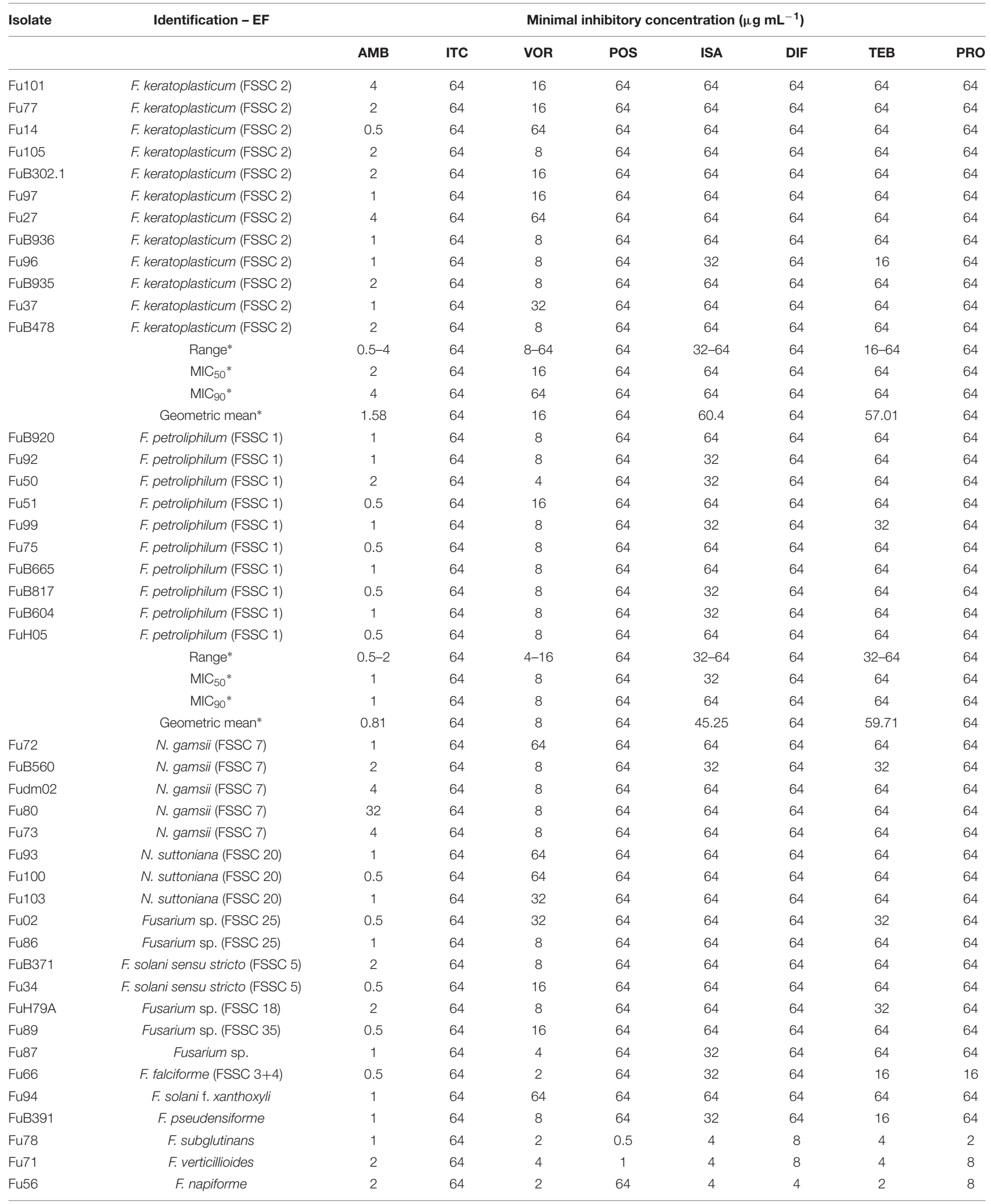

FSSC, Fusarium solani species complex; FFSC, Fusarium fujikuroi species complex; AMB, amphotericin B; ITC, itraconazole; VOR, voriconazole; POS, posaconazole; ISA, isavuconazole; DIF, difenoconazole; TEB, tebuconazole; PRO, propiconazole. *Values calculated for species with sufficient number of isolates. 
The number of reports of Fusarium species that were previously considered to be exclusive plant pathogens but are now implicated in superficial and systemic infections in humans and animals is obviously increasing (Zhang et al., 2006). Fusarium is rather unique in having pathogenic strategies to infect plants as well as animals including humans. This trans-kingdom pathogenicity has been demonstrated for the molecular siblings $F$. falciforme, F. keratoplasticum and F. solani sensu stricto within FSSC (Nalim et al., 2011; Short et al., 2013). Thus, our findings support the concept that Fusarium might serve as good model for studying the genetic basis of trans-kingdom pathogenicity in fungi (Ortoneda et al., 2004).

Our findings agree with reports from different regions in the world where the most frequently identified species causing human infections belonged to the FSSC followed by the fujikuroi and oxysporum species complexes (Al-Hatmi et al., 2015, 2016b; Taj-Aldeen et al., 2016). In Brazil species of FSSC were the most commonly reported, followed by the fujikuroi species complex (Scheel et al., 2013) and oxysporum species complex (Dallé da Rosa et al., 2018). Future studies including larger numbers of isolates are warranted to establish the prevalence of rare Fusarium species in clinical settings. In our study, F. keratoplasticum showed high MIC values $\left(8->32 \mu \mathrm{g} \mathrm{mL}{ }^{-1}\right)$ for most azoles tested and agricultural fungicides, with geometric mean MICs of $1.58 \mu \mathrm{g} \mathrm{mL}-1$ for amphotericin $\mathrm{B}, 16 \mu \mathrm{g} \mathrm{\textrm {mL } ^ { - 1 }}$ for voriconazole and $64 \mu \mathrm{g}$ $\mathrm{mL}^{-1}$ for posaconazole, the most effective drugs against Fusarium species (Lortholary et al., 2016). Rosa et al. (2017) observed that $F$. keratoplasticum was the species most frequently found in onychomycoses lesions and was more susceptible to amphotericin B and voriconazole than the other antifungals tested, with geometric mean MICs of 4.88 and $20.09 \mu \mathrm{g} \mathrm{mL}^{-1}$, respectively, higher than those observed in the present study. A study performed with 89 Fusarium isolates obtained from patients with superficial infections revealed that $49(55.1 \%)$ of isolates belonged to $F$. solani species complex and 40 belonged to F. oxysporum species complex. Most of isolates showed high MIC values to antifungals tested, with modal MIC values of $>16 \mu \mathrm{g} \mathrm{mL} \mathrm{m}^{-1}$ to amphotericin $\mathrm{B}$, itraconazole, voriconazole, and posaconazole (Guevara-Suarez et al., 2016). Itraconazole had no in vitro effect against the isolates tested, which agrees with Tupaki-Sreepurna et al. (2017b). Similarly, Gupta et al. (2016) observed high MIC values of flucytosine, itraconazole, posaconazole, anidulafungin, and caspofungin for clinical isolates of F. keratoplasticum.

In view of the resistance of Fusarium spp. to several antifungal agents, some studies have tested its susceptibility to new antifungals. Abastabar et al. (2018) tested luliconazole, lanoconazole, and efinaconazole against clinical and environmental Fusarium isolates members of the F. fujikuroi species complex $(n=94), F$. solani species complex $(n=14)$,

\section{REFERENCES}

Abastabar, M., Al-Hatmi, A. M. S., Vafaei Moghaddam, M., de Hoog, G. S., Haghani, I., Aghili, S. R., et al. (2018). Potent activities of luliconazole, lanoconazole, and eight comparators against molecularly characterized
F. oxysporum species complex $(n=11), F$. lateritium species complex $(n=1)$, and $F$. graminearum species complex $(n=1)$. Overall, Fusarium species demonstrated lower MICs to luliconazole, lanoconazole and efinaconazole (geometric mean MICs of $0.005,0.013$, and $0.85 \mu \mathrm{g} \mathrm{mL}^{-1}$, respectively) when compared with voriconazole and amphotericin B (geometric mean MICs of 1.37 and $1.9 \mu \mathrm{g} \mathrm{mL}^{-1}$, respectively). In addition, Tupaki-Sreepurna et al. (2017b) tested the susceptibility of F. solani species complex $(n=18), F$. dimerum species complex $(n=2)$, and $F$. incarnatum-equiseti species complex $(n=1)$ to efinaconazole. The concentrations of efinaconazole necessary to inhibited fungal growth vary from 0.031 to $2 \mu \mathrm{g} \mathrm{mL}-1$, with geometric mean MICs varying from 0.08 to $0.7 \mu \mathrm{g} \mathrm{mL}^{-1}$ depending on Fusarium species. These data suggested that luliconazole, lanoconazole and efinaconazole are effective drugs that may be used against fusariosis.

\section{CONCLUSION}

In conclusion, F. keratoplasticum and F. petroliphilum were the most frequent species in this study. Amphotericin B showed lower MICs against Fusarium species whereas the antifungal azoles and the fungicide difenoconazole exhibited higher MICs against FSSC.

\section{ETHICS STATEMENT}

Samples were collected during routine patient care and the study was retrospective, therefore it was determined by the local Institutional Review Board of the Hospital de Clínicas, Federal University of Paraná and CAPES that ethical clearance was not indicated.

\section{AUTHOR CONTRIBUTIONS}

$\mathrm{PH}, \mathrm{AA}-\mathrm{H}, \mathrm{FQ}-\mathrm{T}$, and JM designed the study. PH and AA-H performed the experiments and wrote the first draft. RP, MM, $\mathrm{MN}, \mathrm{FQ}-\mathrm{T}, \mathrm{GH}$, and JM analyzed the data and revised the manuscript. All authors contributed to the writing and approved the final manuscript.

\section{FUNDING}

The work of $\mathrm{PH}$ was supported by Coordination for the Improvement of Higher Education Personnel, but is currently supported by "Instituto Nacional de Ciência e Tecnologia de Inovação em Doenças de Populações Negligenciadas.”

Fusarium species. Antimicrob. Agents Chemother. 62:e0009-18. doi: 10.1128/ AAC.00009-18

Al-Hatmi, A. M. S., Bonifaz, A., de Hoog, G. S., Vazquez-Maya, L., GarciaCarmona, K., Meis, J. F., et al. (2014). Keratitis by Fusarium temperatum, a novel opportunist. BMC Infect. Dis. 14:588. doi: 10.1186/s12879-014-0588-y 
Al-Hatmi, A. M. S., Ahmed, S. A., van Diepeningen, A. D., DrogariApiranthitou, M., Verweij, P. E., Meis, J. F., et al. (2018a). Fusarium metavorans sp. nov.: the frequent opportunist "FSSC6.". Med. Mycol. 56, S144-S152. doi: $10.1093 / \mathrm{mmy} / \mathrm{myx} 107$

Al-Hatmi, A. M. S., Bonifaz, A., Ranque, S., de Hoog, G. S., Verweij, P. E., and Meis, J. F. (2018b). Current antifungal treatment of fusariosis. Int. J. Antimicrob. Agents 51, 326-332. doi: 10.1016/j.ijantimicag.2017.06.017

Al-Hatmi, A. M. S., Hagen, F., Menken, S. B. J., Meis, J. F., and de Hoog, G. S. (2016a). Global molecular epidemiology and genetic diversity of Fusarium, a significant emerging human opportunist from 1958-2015. Emerg. Microbes Infect. 5:e124. doi: 10.1038/emi.2016.126

Al-Hatmi, A. M. S., Meis, J. F., and de Hoog, G. S. (2016b). Fusarium: molecular diversity and intrinsic drug resistance. PLoS Pathog. 12:e1005464. doi: 10.1371/ journal.ppat.1005464

Al-Hatmi, A. M. S., van Diepeningen, A. D., Curfs-Breuker, I., de Hoog, G. S., and Meis, J. F. (2015). Specific antifungal susceptibility profiles of opportunists in the Fusarium fujikuroi complex. J. Antimicrob. Chemother. 70, 1068-1071. doi: $10.1093 /$ jac/dku505

Alvarez-Moreno, C., Lavergne, R.-A., Hagen, F., Morio, F., Meis, J. F., and Le Pape, P. (2017). Azole-resistant Aspergillus fumigatus harboring TR34/L98H, TR46/Y121F/T289A and TR53 mutations related to flower fields in Colombia. Sci. Rep. 7:45631. doi: 10.1038/srep45631

Al-Hatmi, A. M. S., Bonifaz, A., Tirado-Sánchez, A., Meis, J. F., de Hoog, G. S., and Ahmed, S. A. (2017). Fusarium species causing eumycetoma: report of two cases and comprehensive review of the literature. Mycoses 60, 204-212. doi: $10.1111 /$ myc. 12590

Basler, R. (2016). Diversity of Fusarium species isolated from UK forage maize and the population structure of F. graminearum from maize and wheat. PeerJ 4:e2143. doi: $10.7717 /$ peerj. 2143

Boral, H., van Diepeningen, A., Erdem, E., Yağmur, M., de Hoog, G. S., Ilkit, M., et al. (2018). Mycotic keratitis caused by Fusarium solani sensu stricto (FSSC5): a case series. Mycopathologia 183, 835-840. doi: 10.1007/s11046-018-0280-7

Campo, M., Lewis, R. E., and Kontoyiannis, D. P. (2010). Invasive fusariosis in patients with hematologic malignancies at a cancer center: 1998-2009. J. Infect. 60, 331-337. doi: 10.1016/j.jinf.2010.01.010

Carlesse, F., Amaral, A.-P. C., Gonçalves, S. S., Xafranski, H., Lee, M.-L. M., Zecchin, V., et al. (2017). Outbreak of Fusarium oxysporum infections in children with cancer: an experience with 7 episodes of catheter-related fungemia. Antimicrob. Resist. Infect. Control 6:93. doi: 10.1186/s13756-0170247-3

Chiewchanvit, S., Chongkae, S., Mahanupab, P., Nosanchuk, J. D., Pornsuwan, S., Vanittanakom, N., et al. (2017). Melanization of Fusarium keratoplasticum (F. solani species complex) during disseminated fusariosis in a patient with acute leukemia. Mycopathologia 182, 879-885. doi: 10.1007/s11046-017-0156-2

Chowdhary, A., Kathuria, S., Xu, J., and Meis, J. F. (2013). Emergence of azoleresistant Aspergillus fumigatus strains due to agricultural azole use creates an increasing threat to human health. PLoS Pathog. 9:e1003633. doi: 10.1371/ journal.ppat.1003633

Chowdhary, A., Kathuria, S., Xu, J., Sharma, C., Sundar, G., Singh, P. K., et al. (2012). Clonal expansion and emergence of environmental multiple-triazoleresistant Aspergillus fumigatus strains carrying the TR34/L98H mutations in the cyp51A gene in India. PLoS One 7:e52871. doi: 10.1371/journal.pone.0052871

Clark, N., Grim, S., and Lynch, J. (2015). Posaconazole: use in the prophylaxis and treatment of fungal infections. Semin. Respir. Crit. Care Med. 36, 767-785. doi: 10.1055/s-0035-1562902

Clinical and Laboratory Standards Institute [CLSI] (2008). Reference Method for Broth Dilution Antifungal Susceptibility Testing of Filamentous Fungi; Approved Standard. Wayne, PA: CLSI.

Costa, S. S., Matos, K. S., Tessmann, D. J., Seixas, C. D. S., and Pfenning, L. H. (2016). Fusarium paranaense sp. nov., a member of the Fusarium solani species complex causes root rot on soybean in Brazil. Fungal Biol. 120, 51-60. doi: 10.1016/j.funbio.2015.09.005

Dallé da Rosa, P., Nunes, A., Borges, R., Batista, B., Meneghello Fuentefria, A., and Goldani, L. Z. (2018). In vitro susceptibility and multilocus sequence typing of Fusarium isolates causing keratitis. J. Mycol. Med. 28, 482-485. doi: 10.1016/j. mycmed.2018.05.001

de Souza, M., Matsuzawa, T., Lyra, L., Busso-Lopes, A., Gonoi, T., Schreiber, A., et al. (2014). Fusarium napiforme systemic infection: case report with molecular characterization and antifungal susceptibility tests. SpringerPlus 3:492. doi: 10. 1186/2193-1801-3-492

Deising, H. B., Reimann, S., and Pascholati, S. F. (2008). Mechanisms and significance of fungicide resistance. Braz. J. Microbiol. 39, 286-295. doi: 10. 1590/S1517-838220080002000017

Espinel-Ingroff, A., Colombo, A. L., Cordoba, S., Dufresne, P. J., Fuller, J., Ghannoum, M., et al. (2016). International evaluation of MIC distributions and epidemiological cut-off value (ECV) definitions for Fusarium species identified by molecular methods for the CLSI broth microdilution method. Antimicrob. Agents Chemother. 60, 1079-1084. doi: 10.1128/AAC. 02456-15

Fan, J., Urban, M., Parker, J. E., Brewer, H. C., Kelly, S. L., Hammond-Kosack, K. E., et al. (2013). Characterization of the sterol 14 $\alpha$-demethylases of Fusarium graminearum identifies a novel genus-specific CYP51 function. New Phytol. 198, 821-835. doi: 10.1111/nph.12193

García-Ruiz, J. C., Olazábal, I., Adán Pedroso, R. M., López-Soria, L., VelascoBenito, V., Sánchez-Aparicio, J. A., et al. (2015). Disseminated fusariosis and hematologic malignancies, a still devastating association. Report of three new cases. Rev. Iberoam. Micol. 32, 190-196. doi: 10.1016/j.riam.2014.11.003

Gauthier, G. M., and Keller, N. P. (2013). Crossover fungal pathogens: the biology and pathogenesis of fungi capable of crossing kingdoms to infect plants and humans. Fungal Genet. Biol. 61, 146-157. doi: 10.1016/j.fgb.2013.08.016

Geiser, D. M., Jimenez-Gasco, M. D., Kang, S. C., Makalowska, I., Veeraraghavan, N., Ward, T. J., et al. (2004). FUSARIUM-ID v.1.0: a DNA sequence database for identifying Fusarium. Eur. J. Plant Pathol. 110, 473-479.

Guevara-Suarez, M., Cano-Lira, J. F., Cepero de García, M. C., Sopo, L., De Bedout, C., Cano, L. E., et al. (2016). Genotyping of Fusarium isolates from onychomycoses in Colombia: detection of two new species within the Fusarium solani species complex and in vitro antifungal susceptibility testing. Mycopathologia 181, 165-174. doi: 10.1007/s11046-016-9983-9

Gupta, C., Jongman, M., Das, S., Snehaa, K., Bhattacharya, S. N., Seyedmousavi, S., et al. (2016). Genotyping and in vitro antifungal susceptibility testing of Fusarium isolates from onychomycosis in India. Mycopathologia 181, 497-504. doi: 10.1007/s11046-016-0014-7

Hassan, A. S., Al-Hatmi, A. M. S., Shobana, C. S., van Diepeningen, A. D., Kredics, L., Vágvölgyi, C., et al. (2016). Antifungal susceptibility and phylogeny of opportunistic members of the genus Fusarium causing human keratomycosis in South India. Med. Mycol. 54, 287-294. doi: 10.1093/mmy/myv105

Hof, H. (2001). Critical annotations to the use of azole antifungals for plant protection. Antimicrob. Agents Chemother. 45, 2987-2990. doi: 10.1128/AAC. 45.11.2987-2990.2001

Kassar, O., Charfi, M., Trabelsi, H., Hammami, R., and Elloumi, M. (2016). Fusarium solani endocarditis in an acute leukemia patient. Med. Mal. Infect. 46, 57-59. doi: 10.1016/j.medmal.2015.11.004

Katiyar, S. K., and Edlind, T. D. (2009). Role for Fks1 in the intrinsic echinocandin resistance of Fusarium solani as evidenced by hybrid expression in Saccharomyces cerevisiae. Antimicrob. Agents Chemother. 53, 1772-1778. doi: 10.1128/AAC.00020-09

Khodavaisy, S., Badali, H., Rezaie, S., Nabili, M., Moghadam, K. G., Afhami, S., et al. (2016). Genotyping of clinical and environmental Aspergillus flavus isolates from Iran using microsatellites. Mycoses 59, 220-225. doi: 10.1111/myc.12451

Kim, S. W., Park, J. K., Lee, C. H., Hahn, B.-S., and Koo, J. C. (2016). Comparison of the antimicrobial properties of chitosan oligosaccharides (COS) and EDTA against Fusarium fujikuroi causing rice bakanae disease. Curr. Microbiol. 72, 496-502. doi: 10.1007/s00284-015-0973-9

Lortholary, O., Fernández-Ruiz, M., and Perfect, J. R. (2016). The current treatment landscape: other fungal diseases (cryptococcosis, fusariosis and mucormycosis). J. Antimicrob. Chemother. 71, ii31-ii36.

Lortholary, O., Obenga, G., Biswas, P., Caillot, D., Chachaty, E., Bienvenu, A.L., et al. (2010). International retrospective analysis of 73 cases of invasive fusariosis treated with voriconazole. Antimicrob. Agents Chemother. 54, 4446-4450. doi: 10.1128/AAC.00286-10

Manzo, D., Ferriello, F., Puopolo, G., Zoina, A., D’Esposito, D., Tardella, L., et al. (2016). Fusarium oxysporum f.sp. Radicis-lycopersici induces distinct transcriptome reprogramming in resistant and susceptible isogenic tomato lines. BMC Plant Biol. 16:53. doi: 10.1186/s12870-016-0740-5

Meis, J. F., Chowdhary, A., Rhodes, J. L., Fisher, M. C., and Verweij, P. E. (2016). Clinical implications of globally emerging azole resistance in Aspergillus 
fumigatus. Philos. Trans. R. Soc. Lond. B. Biol. Sci. 371:20150460. doi: 10.1098/ rstb.2015.0460

Milicevic, D. R., Skrinjar, M., and Baltic, T. (2010). Real and perceived risks for mycotoxin contamination in foods and feeds: challenges for food safety control. Toxins 2, 572-592. doi: 10.3390/toxins2040572

Muraosa, Y., Oguchi, M., Yahiro, M., Watanabe, A., Yaguchi, T., and Kamei, K. (2017). Epidemiological study of Fusarium species causing invasive and superficial fusariosis in Japan. Med. Mycol. J. 58, E5-E13. doi: 10.3314/mmj. 16-00024

Nalim, F. A., Samuels, G. J., Wijesundera, R. L., and Geiser, D. M. (2011). New species from the Fusarium solani species complex derived from perithecia and soil in the Old World tropics. Mycologia 103, 1302-1330. doi: 10.3852/ 10-307

Nucci, F., Nouer, S., Capone, D., Anaissie, E., and Nucci, M. (2015). Fusariosis. Semin. Respir. Crit. Care Med. 36, 706-714. doi: 10.1055/s-0035-1562897

Nucci, M., and Anaissie, E. (2007). Fusarium infections in immunocompromised patients. Clin. Microbiol. Rev. 20, 695-704. doi: 10.1128/CMR. 00014-07

Nucci, M., Anaissie, E. J., Queiroz-Telles, F., Martins, C. A., Trabasso, P., Solza, C., et al. (2003). Outcome predictors of 84 patients with hematologic malignancies and Fusarium infection: Fusarium prognostic factors. Cancer 98, 315-319. doi: $10.1002 /$ cncr. 11510

Nucci, M., Marr, K. A., Queiroz-Telles, F., Martins, C. A., Trabasso, P., Costa, S., et al. (2004). Fusarium infection in hematopoietic stem cell transplant recipients. Clin. Infect. Dis. 38, 1237-1242. doi: 10.1086/ 383319

Nucci, M., Marr, K. A., Vehreschild, M. J. G. T., de Souza, C. A., Velasco, E., Cappellano, P., et al. (2014). Improvement in the outcome of invasive fusariosis in the last decade. Clin. Microbiol. Infect. 20, 580-585. doi: 10.1111/1469-0691. 12409

Nucci, M., Shoham, S., Abdala, E., Hamerschlak, N., Rico, J. C., Forghieri, F., et al. (2019). Outcomes of patients with invasive fusariosis who undergo further immunosuppressive treatments, is there a role for secondary prophylaxis? Mycoses doi: 10.1111/myc.12901 [Epub ahead of print].

Nucci, M., Varon, A. G., Garnica, M., Akiti, T., Barreiros, G., Trope, B. M., et al. (2013). Increased incidence of invasive fusariosis with cutaneous portal of entry, Brazil. Emerg. Infect. Dis. 19, 1567-1572. doi: 10.3201/eid1910. 120847

O’Donnell, K., Kistler, H. C., Cigelnik, E., and Ploetz, R. C. (1998). Multiple evolutionary origins of the fungus causing Panama disease of banana: concordant evidence from nuclear and mitochondrial gene genealogies. Proc. Natl. Acad. Sci. U.S.A. 95, 2044-2049.

O’Donnell, K., Sarver, B. A., Brandt, M., Chang, D. C., Noble-Wang, J., Park, B. J., et al. (2007). Phylogenetic diversity and microsphere array-based genotyping of human pathogenic Fusaria, including isolates from the multistate contact lens-associated U.S. keratitis outbreaks of 2005 and 2006. J. Clin. Microbiol. 45, 2235-2248.

O’Donnell, K., Sutton, D. A., Rinaldi, M. G., Sarver, B. A., Balajee, S. A., Schroers, H. J., et al. (2010). Internet-accessible DNA sequence database for identifying fusaria from human and animal infections. J. Clin. Microbiol. 48, 3708-3718. doi: 10.1128/JCM.00989-10

O’Donnell, K., Sutton, D. A., Wiederhold, N., Robert, V. A. R. G., Crous, P. W., and Geiser, D. M. (2016). Veterinary fusarioses within the United States. J. Clin. Microbiol. 54, 2813-2819. doi: 10.1128/JCM.01607-16

Ortoneda, M., Guarro, J., Madrid, M. P., Caracuel, Z., Roncero, M. I. G., Mayayo, E., et al. (2004). Fusarium oxysporum as a multihost model for the genetic dissection of fungal virulence in plants and mammals. Infect. Immun. 72, 1760-1766. doi: 10.1128/IAI.72.3.1760-1766.2004

Rosa, P. D., Heidrich, D., Corrêa, C., Scroferneker, M. L., Vettorato, G., Fuentefria, A. M., et al. (2017). Genetic diversity and antifungal susceptibility of Fusarium isolates in onychomycosis. Mycoses 60, 616-622. doi: 10.1111/myc. 12638

Salah, H., Al-Hatmi, A. M., Theelen, B., Abukamar, M., Hashim, S., van Diepeningen, A. D., et al. (2015). Phylogenetic diversity of human pathogenic Fusarium and emergence of uncommon virulent species. J. Infect. 71, 658-666. doi: 10.1016/j.jinf.2015.08.011
Sandoval-Denis, M., and Crous, P. W. (2018). Removing chaos from confusion: assigning names to common human and animal pathogens in Neocosmospora. Persoonia 41, 109-129. doi: 10.3767/persoonia.2018. 41.06

Scheel, C. M., Hurst, S. F., Barreiros, G., Akiti, T., Nucci, M., and Balajee, S. A. (2013). Molecular analyses of Fusarium isolates recovered from a cluster of invasive mold infections in a Brazilian hospital. BMC Infect. Dis. 13:49. doi: 10.1186/1471-2334-13-49

Short, D. P. G., O’Donnell, K., Thrane, U., Nielsen, K. F., Zhang, N., Juba, J. H., et al. (2013). Phylogenetic relationships among members of the Fusarium solani species complex in human infections and the descriptions of $F$. keratoplasticum sp. nov. and F. petroliphilum stat. nov. Fungal Genet. Biol. 53, 59-70. doi: 10.1016/j.fgb.2013.01.004

Sierra-Hoffman, M., Paltiyevich-Gibson, S., Carpenter, J. L., and Hurley, D. L. (2005). Fusarium osteomyelitis: case report and review of the literature. Scand. J. Infect. Dis. 37, 237-240. doi: 10.1080/0036554041002 1036

Singh, R. P., Singh, P. K., Rutkoski, J., Hodson, D. P., He, X., Jørgensen, L. N., et al. (2016). Disease impact on wheat yield potential and prospects of genetic control. Annu. Rev. Phytopathol. 54, 303-322. doi: 10.1146/annurev-phyto080615-095835

Snelders, E., van der Lee, H. A. L., Kuijpers, J., Rijs, A. J. M. M., Varga, J., Samson, R. A., et al. (2008). Emergence of azole resistance in Aspergillus fumigatus and spread of a single resistance mechanism. PLoS Med. 5:e219. doi: 10.1371/ journal.pmed.0050219

Sobrova, P., Adam, V., Vasatkova, A., Beklova, M., Zeman, L., and Kizek, R. (2010). Deoxynivalenol and its toxicity. Interdiscip. Toxicol. 3, 94-99. doi: 10.2478/ v10102-010-0019-x

$\mathrm{Su}, \mathrm{C}$., Hsu, H., Wu, J., and Chou, C. (2007). Diagnosis of fusariosis in urine cytology. J. Clin. Pathol. 60, 422-424. doi: 10.1136/jcp.2006.038489

Summerbell, R. C., and Scott, J. A. (2016). "Conidiogenesis: Its evolutionary aspects in the context of a philosophy of opportunity (lectics)," in Biology of Microfungi Fungal Biology, ed. D.-W. Li (Cham: Springer International Publishing), 169-195. doi: 10.1007/978-3-319-29137-6-8

Taj-Aldeen, S. J., Salah, H., Al-Hatmi, A. M., Hamed, M., Theelen, B., van Diepeningen, A. D., et al. (2016). In vitro resistance of clinical Fusarium species to amphotericin B and voriconazole using the EUCAST antifungal susceptibility method. Diagn. Microbiol. Infect. Dis. 85, 438-443. doi: 10.1016/j.diagmicrobio. 2016.05.006

Tamura, K., Stecher, G., Peterson, D., Filipski, A., and Kumar, S. (2013). MEGA6: molecular evolutionary genetics analysis version 6.0. Mol. Biol. Evol. 30, 2725-2729. doi: 10.1093/molbev/mst197

Tortorano, A. M., Richardson, M., Roilides, E., Diepeningen, A., van Caira, M., Munoz, P., et al. (2014). ESCMID and ECMM joint guidelines on diagnosis and management of hyalohyphomycosis: Fusarium spp., Scedosporium spp. and others. Clin. Microbiol. Infect. 20, 27-46. doi: 10.1111/1469-0691. 12465

Tupaki-Sreepurna, A., Al-Hatmi, A. M. S., Kindo, A. J., Sundaram, M., and de Hoog, G. S. (2017a). Multidrug-resistant Fusarium in keratitis: a clinicomycological study of keratitis infections in Chennai, India. Mycoses 60, 230-233. doi: 10.1111/myc.12578

Tupaki-Sreepurna, A., Jishnu, B. T., Thanneru, V., Sharma, S., Gopi, A., Sundaram, M., et al. (2017b). An assessment of in vitro antifungal activities of efinaconazole and itraconazole against common nondermatophyte fungi causing onychomycosis. J. Fungi 3:20. doi: 10.3390/jof302 0020

van Diepeningen, A. D., Al-Hatmi, A. M. S., Brankovics, B., and de Hoog, G. S. (2014). Taxonomy and clinical spectra of Fusarium species: where do we stand in 2014? Curr. Clin. Microbiol. Rep. 1, 10-18. doi: 10.1007/s40588-0140003-x

van Diepeningen, A. D., and de Hoog, G. S. (2016). Challenges in Fusarium, a trans-kingdom pathogen. Mycopathologia 181, 161-163. doi: 10.1007/s11046016-9993-7

Verweij, P. E., Chowdhary, A., Melchers, W. J. G., and Meis, J. F. (2016). Azole resistance in Aspergillus fumigatus: can we retain the clinical use of mold-active antifungal azoles? Clin. Infect. Dis. 62, 362-368. doi: 10.1093/cid/ civ885 
Walther, G., Stasch, S., Kaerger, K., Hamprecht, A., Roth, M., Cornely, O. A., et al. (2017). Fusarium keratitis in Germany. J. Clin. Microbiol. 55, 2983-2995. doi: 10.1128/JCM.00649-17

Zhang, N., O'Donnell, K., Sutton, D. A., Nalim, F. A., Summerbell, R. C., Padhye, A. A., et al. (2006). Members of the Fusarium solani species complex that cause infections in both humans and plants are common in the environment. J. Clin. Microbiol. 44, 2186-2190. doi: 10.1128/JCM.00120-06

Conflict of Interest Statement: JM received grants from F2G and Merck. He has been a consultant to Scynexis and Merck and received speaker's fees from Merck, United Medical, TEVA and Gilead Sciences.
The remaining authors declare that the research was conducted in the absence of any commercial or financial relationships that could be construed as a potential conflict of interest.

Copyright ( 2019 Herkert, Al-Hatmi, de Oliveira Salvador, Muro, Pinheiro, Nucci, Queiroz-Telles, de Hoog and Meis. This is an open-access article distributed under the terms of the Creative Commons Attribution License (CC BY). The use, distribution or reproduction in other forums is permitted, provided the original author(s) and the copyright owner(s) are credited and that the original publication in this journal is cited, in accordance with accepted academic practice. No use, distribution or reproduction is permitted which does not comply with these terms. 